\title{
Bayesian principles or Gestalt perception for clinical judgment
}

\author{
Federico Vancheri
}

Received: 9 August 2014/Accepted: 16 September 2014/Published online: 7 October 2014

(C) SIMI 2014

\section{Dear Editor,}

I agree with the distinction between Bayesian and Gestalt patterns in clinical judgment described by Gianfranco Cervellin et al. [1]. This corresponds to the dual-process theory of thinking [2]. According to cognitive psychological studies, there are two fundamental approaches to decision-making: intuitive and analytical [3, 4]. The intuitive approach, also termed System 1, is unconscious, "fast and frugal," characterized by heuristics, or strategies that provide shortcuts to quick decisions, and vulnerable to biases [5]. This model implies non-analytical reasoning, based on pattern recognition. This is the process of matching the presentation of symptoms and signs of a new patient with disease features of a previously encountered patient retrieved from memory. This process is based on pre-stored networks of disease characteristics produced by clinicians' knowledge and past experiences, which is termed illness script. It often leads to good judgments, but when the patient presentation is atypical, it may fail. Moreover, the system is highly influenced by the context, which includes patient and physicians non-medical factors, such as appearance, age, gender, or workload.

On the other hand, the analytical process, or System 2, is based on conscious and rational reasoning. It is a step by step process where hypotheses are generated or discarded at each step; hypothetic-deductive, as each hypothesis is used to predict which additional findings ought to be present if it is true; probabilistic and Bayesian, in the sense that hypotheses are confirmed or dismissed according to their probability. The analytical process is slow but effective when a patient presentation is not readily recognized, and previous experience cannot inform judgments. The two components of the dual-process model are not independent but there is a continuum between them with reciprocal influences. These observations indicate that clinical judgment is a complex process. This should be taken into account in clinical practice. For this reason, medical teaching should involve problem-solving strategies and hypothesis generation and testing [6].

Conflict of interest None.

\section{References}

1. Cervellin G, Borghi L, Lippi G (2014) Do clinicians decide relying primarily on Bayesians principles or on Gestalt perception? Some pearls and pitfalls of Gestalt perception in medicine. Intern Emerg Med 9:513-519

2. Kahneman D (2012) Pensieri lenti e veloci: Mondadori Editore

3. Croskerry P (2009) A universal model of diagnostic reasoning. Acad Med 84:1022-1028

4. Norman G (2009) Dual processing and diagnostic errors. Adv Health Sci Educ 14:37-49

5. Gigerenzer G, Gaissmaier W (2011) Heuristic decision making. Annu Rev Psychol 62:451-482

6. Pagliaro L, Bobbio M, Colli A (2011) La diagnosi in medicina. Storia, strumenti, scenari e incertezze nell'incontro tra paziente e medico: Raffaello Cortina Editore
F. Vancheri $(\bowtie)$

Ospedale S.Elia, Caltanissetta, Italy

e-mail: fvanche@tin.it 